\title{
0 Plano Nacional de Banda Larga Brasileiro: um estudo de seus limites e efeitos sociais e políticos
} André Lemos e Francisco Paulo Jamil Almeida Marques

\section{Resumo}

0 trabalho examina os limites e os possíveis efeitos sociais e políticos do Plano Nacional de Banda Larga (PNBL). A discussão considera as transformações testemunhadas no cenário das telecomunicações brasileiras ao longo da segunda metade do século XX. Por um lado, o fim do monopólio estatal das telecomunicações e a venda de empresas públicas para a iniciativa privada trouxeram maiores investimentos em infraestrutura. Por outro lado, a atuação dos agentes do Estado brasileiro ainda não parece ter surtido o efeito desejado no que se refere à universalização e ao barateamento na oferta de serviços de telecomunicações. 0 PNBL foi lançado com o objetivo de combater tais dificuldades. 0 projeto, no entanto, peca no que se refere (1) à baixa velocidade de conexão a ser oferecida aos usuários; (2) aos preços pouco atrativos; e (3) à ausência de reflexão acerca da importância da neutralidade da rede. Defende-se que apenas ao contemplar tais aspectos o Plano poderá garantir inovação, crescimento econômico, pluralidade informacional e liberdade de acesso.

\section{Palavras-Chave}

Internet. Políticas de Comunicação. Plano Nacional de Banda Larga. Inclusão Digital. Neutralidade da Rede.

André Lemos I andre@andrelemos.info Doutor em Sociologia pela Université Paris V (René Descartes). Professor Associado da Faculdade de Comunicação da Universidade Federal da Bahia (UFBA).

\section{Francisco Paulo Jamil Almeida Marques I} marquesjamil@gmail.com Doutor em Comunicação e Cultura Contemporâneas pela Universidade Federal da Bahia (UFBA). Professor adjunto do Instituto de Cultura e Arte da Universidade Federal do Ceará (UFC).

\section{Introdução}

Há uma série de estudos e relatórios que apontam o Brasil como um dos maiores expoentes da atual cultura digital. ${ }^{1}$ Este fenômeno ocorre não obstante os altos custos de conexão e a escassa cobertura provida por operadoras em regiões distantes das grandes metrópoles. 0 Plano Nacional de Banda Larga (PNBL), projeto proposto pelo Governo brasileiro em $2010 \mathrm{e}$ implementado em 2011, tem o intuito de atacar tais dificuldades, diminuindo os preços cobrados pelo acesso à internet e oferecendo possibilidades de conexão por todo o país.

Após uma série de tentativas (espalhadas em experiências de âmbito municipal, estadual e federal) para se combater a exclusão digital a partir da criação de telecentros, da aquisiçãa de computadores para escolas públicas e da esporádica isenção ou diminuição de impostos sobre produtos da área de informática, percebeuse que 0 acesso às máquinas não é suficiente (COSTA, 2007; LEMOS, 2007). 0 provimento de alternativas para conexão (rápida, barata e 
estável) à internet passou a constar da pauta das políticas governamentais em níveis estadual e federal.

Quais as características do PNBL? Como serão resolvidos os focos de tensão gerados a partir do momento em que as operadoras de telecomunicações - que há mais de uma década são responsáveis pela prestação de serviços de internet - devem conviver com um perfil mais intervencionista dos agentes públicos? Em que medida o PNBL se mostra apropriado para responder aos desafios que se colocam usuários, empresas e governos? 0 objetivo deste artigo é tentar responder a essas perguntas e refletir acerca dos efeitos e dos limites do atual PNBL.

0 texto apresenta 0 atual marco regulatório brasileiro, completamente modificado após a quebra do monopólio das telecomunicações ocorrida no final dos anos 1990. Esta discussão permite compreender a correlação de forças que envolve usuários, empresas e governos há mais de uma década. Para fins de contextualização, apresentamse dados sobre o uso das telecomunicações (sobretudo da internet) no Brasil.

Se, por um lado, os brasileiros integram um mercado consumidor em franca expansão no setor de telecomunicações, por outro lado, são nítidas as dificuldades para se usufruir dos serviços de comunicação digital no país. A telefonia móvel, por exemplo, bate recordes de criação de linhas a cada mês, mas a maioria destas adesões se refere ao serviço pré-pago, uma vez que muitos usuários não têm condições de arcar com as despesas relacionadas (a) aos custos de operação e (b) à alta carga tributária testemunhada no Brasil. As tensões concernentes à resistência declarada de algumas empresas de telecomunicações em expandir o serviço de conexão à internet para áreas menos rentáveis também são discutidas. Por fim, o artigo aponta para o problema da neutralidade da rede e da inclusão digital, questões centrais para a compreensão do PNBL.

\section{0 contexto das telecomunicações brasileiras}

Desde o Decreto $\mathrm{n}^{0} 3.296$, de 1917, voltado para afirmar a "[...] exclusiva competência do Governo Federal os serviços radiotelegráfico e radiotelefônico no território brasileiro", até a última década do século $\mathrm{XX}$, percebe-se uma forte marca da centralização dos serviços de telecomunicações nas mãos do Estado brasileiro.

0 desenvolvimento e a maior adoção dos suportes de radiodifusão, a partir da década de 1930, geraram uma nova pauta de preocupações para 0 Governo. Além da transmissão, possibilitada pelas tecnologias de telecomunicações, considerou- 
se necessário manter vigilância sobre o tipo de conteúdo oferecido por emissoras de rádio e, posteriormente, de televisão, ainda que 0 Estado não fosse o responsável principal pela sua produção. 0 presidente Getúlio Vargas, tanto no período em que governou como ditador (1937-1945), quanto no intervalo em que atuou como mandatário eleito (1951-1954), considerou essencial acompanhar, ou mesmo censurar, a elaboração de materiais que pudessem influenciar na formação da imagem pública do governo e de seus opositores (JAMBEIR0 et al., 2004).

Mesmo que o impacto da televisão e do rádio na formação da opinião pública tenha permanecido no horizonte de preocupações dos dirigentes políticos brasileiros durante boa parte da primeira metade do século XX, é somente a partir da década de 1960 que se verifica uma maior dedicação do Estado em montar uma infraestrutura de comunicações apta a interligar todo o país.

Até a década de 1960, o Brasil ainda passava pela fase de implantação de seu sistema de telecomunicações (SUNDFELD, 2006, p. 2). As operadoras de telecomunicações atuavam em âmbito local, sendo que apenas o sistema de telégrafos, e algumas emissoras de TV, estavam sob controle da União. Dos anos 1960 em diante, o quadro é substancialmente modificado.

A estratégia dos governos à época consistiu em montar um arranjo institucional que dividiu a responsabilidade pela operação do setor de telecomunicações (que ficou a cargo de empresas públicas, em um sistema de monopólio) e a operação da área de radiodifusão (com forte influência privada desde seu início, apesar da existência de emissoras diretamente controladas por instituições do Estado).

A aprovação e a entrada em vigor, em 1962, do Código Brasileiro de Telecomunicações (CBT), instrumento que regulamentou por várias décadas tanto as telecomunicações quanto a radiodifusão no Brasil, foi um dos fatores fundamentais para que se consolidasse este novo momento, que Sundfeld (2006, p. 2) denomina de "fase de estatização" dos serviços de telefonia. Esse momento duraria até a década de 1990.

Ao tomar o poder em 1964, os militares mantiveram estrita observação sobre 0 setor das comunicações. Eles tinham como objetivo implementar uma doutrina de segurança nacional (o que demanda domínio estratégico sobre, por exemplo, telecomunicações via satélite). Ao mesmo tempo, as Forças Armadas se preocupavam com a fabricação de uma opinião pública a elas favorável, exercendo influência (ou mesmo controle) sobre a radiodifusão e a atuação de veículos impressos. A dedicação dos militares ficou evidente ao editarem duas medidas: o Decreto-lei ${ }^{0} 200$, de 1967, que trata da criação do Ministério das Comunicações, voltado para estabelecer políticas especificamente para as telecomunicações e para a radiodifusão; e o Decreto-lei no 236, também de 1967, que revogou 
41 dispositivos do CBT (aprovado cinco anos antes) e acrescentou outros 14 artigos ao Código, passando-se a prever, por exemplo, punições mais duras no caso de um uso das comunicações distinto daquele previsto pelo governo. 0 Código Brasileiro de Telecomunicações (CBT) passou por outras alterações pontuais durante as décadas de 1970 e 1980, mas apenas com a redemocratização do país e com a promulgação de uma nova Constituição Federal, em 1988, este dispositivo perdeu a maior parte de sua força.

A criação da Telebrás, em 1972, foi uma das maiores mudanças, no setor de telecomunicações, promovida pelos militares nessa época. A empresa era, então, uma holding de 28 empresas (Embratel +27 prestadoras estaduais) cujo objetivo foi unificar os serviços de telefonia e permitir a operação do monopólio estatal na área.

Ressalte-se que não foram apenas modificações no plano político que influenciaram a área de telecomunicações no Brasil ao longo dos últimos anos. De acordo com Ramos (2000), os aspectos tecnológicos (a convergência entre telecomunicações, informática e produção de conteúdo de comunicação), a internacionalização (tanto no que se refere à oferta e consumo de materiais midiáticos, quanto em relação à área de abrangência de empresas provedoras de serviços de telecomunicações) e a ampliação no leque de atores engajados no debate sobre regulamentação (afinal, a Constituição passou a ver com bons olhos a interferência da esfera civil no processo de produção da decisão política) constituem transformações cuja compreensão é fundamental para se ter um panorama adequado do setor no Brasil contemporâneo e do atual PNBL.

Pode-se afirmar que a principal transformação na área se deu com a quebra do monopólio das telecomunicações ao longo dos anos 1990. Esse processo integrou o conjunto de estratégias adotadas pelo Governo a fim de atrair investimentos estrangeiros (a meta era estimular a recuperação da atividade econômica após a crise vivenciada na década anterior). A fase de flexibilização na área de telecomunicações, iniciada em 1995 (quando houve a aprovação da emenda constitucional que permitiu a quebra do monopólio estatal), abriu espaço para uma etapa posterior, a privatização (SUNDFELD, 2006).

0 leilão das empresas que integravam 0 sistema Telebrás ocorreu em julho de 1998; a holding foi desmembrada em 12 empresas, tendo 0 Estado Brasileiro se retirado da operação do setor e passado a atuar através de uma entidade reguladora, a Agência Nacional de Telecomunicações (Anatel), com funções de definir tarifas, aplicar multas e aprovar concessões. A diretriz jurídica fundamental seguida por parte da Agência, a Lei Geral de Telecomunicações (LGT, Lei n ${ }^{0}$ 9.472/97), havia sido aprovada em 1997.

A Lei Geral de Telecomunicações revogou boa parte do já desatualizado Código Brasileiro de 
Telecomunicações, aprofundando a diferença, em termos de regulamentação, das áreas de telecomunicações (a qual o Estado, agora, apenas fiscaliza, e não mais opera) e de radiodifusão (mantida, basicamente, nas mãos de empresas privadas, que atuam por meio de concessões).

Não há dúvidas de que a privatização das telecomunicações trouxe benefícios à sociedade brasileira atendendo uma demanda reprimida na área de telefonia ${ }^{2}$ e fixando metas de universalização dos serviços de telecomunicações. Houve também um maior investimentos para o setor, inclusive com a entrada de capital estrangeiro.

Por outro lado, o processo de desestatização havia previsto, em um cenário ideal, maior concorrência no setor, o que tenderia a baixar os preços praticados pelo mercado. No entanto, não foi isso o que aconteceu, tanto em grandes cidades quanto no interior do país. Em muitas áreas rurais, há serviços que nem sequer são prestados com regularidade. Hoje é, certamente, mais fácil e rápido adquirir uma linha de telefone em determinados locais, mas os custos do serviço são cada vez mais altos. Há também uma excessiva tributação, que dificulta uma ampla adoção dos serviços por parte da população.

Pode-se dizer que o período atual de "pósprivatização" (SUNDFELD, 2006, p. 8) testemunhou a consolidação de uma nova realidade na qual os embates na área de telecomunicações passam a se constituir por tensões entre governo e empresas privadas. A correlação de forças é testemunhada, por exemplo, na pressão que o governo vem exercendo nos últimos anos para que os serviços de conexão à internet sejam aperfeiçoados. 0 PNBL será mais um teste para ver se os princípios de universalização, barateamento e melhoria do acesso à internet no país, assumidos pelo Governo Federal, poderão vingar em um ambiente onde os interesses das empresas privadas (nem sempre ajustados aos do Governo) quase sempre têm prevalecido.

\section{0 novo cenário das telecomunicações: dados sobre 0 uso da internet no Brasil}

A privatização das telecomunicações ofereceu ao Brasil um novo patamar para o desenvolvimento da comunicação digital. 0 número de linhas de telefones celulares, por exemplo, saltou de 800 mil em 1994 para 7,4 milhões em 1998 (ANATEL, 2011). Já em setembro de 2011, a Anatel registrou mais de 227,4 milhões de linhas de telefonia móvel (sendo que a população atual do país é de aproximadamente 193 milhões de pessoas). (BRASIL..., 2011) A quantidade de usuários com acesso à internet também aumentou de forma consistente. Em julho de 2011, o Ibope Nielsen 
Online informou que o Brasil havia alcançado a marca de 58,6 milhões de pessoas com acesso à internet (considerando-se apenas os usuários que têm acesso à rede no trabalho e em seus domicílios) (BRASILEIROS COM ACESSO..., 2011). Um ano e meio antes, em janeiro de 2010, o levantamento indicava 46,8 milhões de usuários (INTERNAUTAS..., 2010).

Apesar dos problemas de acesso e dos altos custos, a cultura digital brasileira floresce. $0 \mathrm{~s}$ brasileiros são os usuários que mais tempo passam conectados à internet. Segundo pesquisa do Ibope/NetRatings, em janeiro de 2007, os usuários do Brasil gastavam, em média, 21 horas e 20 minutos por mês navegando (TEMP0..., 2007). Em fevereiro de 2010, os dados indicavam que os brasileiros ficavam conectados por 26,4 horas mensalmente (TOZZETO, 2010). Ao apresentar dados coletados em fevereiro de 2011, no relatório Comparing Global Internet Connections, a consultoria The Nielsen Company revelou que, dentre os nove países então pesquisados, ${ }^{3}$ os brasileiros atingiram o topo na quantidade de tempo gasto online, chegando a uma média de 30 a 31 horas por mês (SWISS..., 2011).

De forma paradoxal, o mesmo documento mostra que 0 Brasil lidera, em termos percentuais, a quantidade de usuários que acessa a internet com velocidade lenta. A The Nielsen Company classificou a velocidade de acesso em quatro grupos:
- Velocidade de navegação lenta: até 512 Kbps;

- Velocidade de navegação média: de 512 Kbps a 2 Mbps;

- Velocidade de navegação rápida: de 2 a 8 Mbps; e - Velocidade de navegação super-rápida: acima de 8 Mbps.

A faixa correspondente à velocidade de navegação média é utilizada por 48\% dos usuários de internet no Brasil. Em todos os outros 8 países, a maioria dos acessos se dá a partir de conexões rápidas (entre 2 e 8 Mbps). 0 cenário de velocidade de acesso mais próximo da realidade brasileira se encontra na Itália. Enquanto neste país os usuários com conexão lenta e com conexão superrápida representam 7\% em cada faixa, no Brasil, $31 \%$ dos internautas navegam com velocidade abaixo de 512 Kbps e somente $6 \%$ usufruem de conexões com velocidade acima de $8 \mathrm{Mbps}$ (SWISS..., 2011).

Em março de 2011, a Federação das Indústrias do Estado do Rio de Janeiro (FIRJAN) divulgou um relatório indicando que as empresas brasileiras pagam por um serviço de banda larga mais caro do que em países como Alemanha, Canadá e Estados Unidos, sem necessariamente haver incremento na qualidade do serviço. De acordo com o relatório, a conexão de 1 Mbps custa no Brasil, em média, US\$ 
42,73 por mês. 0 valor na Alemanha é de US $\$ 9,30$ mensais; no México e na Colômbia os valores são, respectivamente, US\$16,5 e US\$16,7; no Canadá, paga-se US\$28,60; já nos Estados Unidos, o valor chega a US $\$ 40$.

\footnotetext{
No Brasil, para a tecnologia de banda larga DSL para empresas, o custo de acesso é de $\mathrm{R} \$ 70,85$ [US\$ 41,67] em média para o pacote com velocidade de download de $1 \mathrm{Mbps}$, considerada como mínima necessária para atender as necessidades mais simples de micro e pequenas empresas. Esse custo, porém, não é igual para todos os estados. De fato, ele varia $650 \%$ no país, tendo valor mínimo de $\mathrm{R} \$ 57,40$ [US\$ 33,76] nos estados de Alagoas e Espírito Santo e o valor máximo de R $\$ 429,90$ [US\$ 252,88] no Amapá, onde a velocidade máxima disponivel é de apenas 600 kbps (FIRJAN, 2011, p. 5).
}

Conforme pode ser observado, a questão apontada no relatório da FIRJAN não se refere apenas à baixa velocidade e ao preço alto. Refere-se, também, à desigualdade no perfil das conexões testemunhada entre diferentes regiões do Brasil. É verdade que a quantidade de lares com computadores e com acesso à internet vem aumentando de maneira substancial nos últimos anos. De acordo com o Instituto Brasileiro de Geografia e Estatística (IBGE), no ano de 2009, 27,4\% dos domicílios pesquisados possuíam acesso à internet; em 2008, esse número era de $23,8 \%$. A mesma pesquisa aponta que, em 2009, 67,9 milhões e brasileiros acima de 10 anos de idade afirmaram utilizar a internet. (IBGE, 2010) Quatro anos antes, em 2005, o registro correspondeu a somente 31,9 milhões de usuários. No intervalo 2005-2009, assim, o aumento no número de internautas no Brasil foi de 112,9\%. Contudo, a mesma pesquisa revelou que, na região Sudeste, a mais rica do país, os lares que possuíam computador (nem todos com acesso à internet, ressalte-se) respondiam por 43,7\% da amostra. 0 índice é bem superior aos dados verificados em regiões mais pobres, como a Norte (onde os computadores se fazem presentes em 13,2\% dos lares) e a Nordeste (com 14,4\% dos domicílios pesquisados a possuírem computadores). ${ }^{4}$

\subsection{Governo e operadoras de telecomunicações: divergências no período recente}

$$
\begin{aligned}
& \text { Os dados até aqui apresentados permitem } \\
& \text { constatar a dinâmica da cultura digital no Brasil. } \\
& \text { Vimos que os brasileiros enfrentam dificuldades de } \\
& \text { conexão quando comparados a usuários de outros } \\
& \text { países; e mesmo entre os brasileiros, é sensível } \\
& \text { a discrepância no que concerne aos índices de }
\end{aligned}
$$

Ainda sobre os custos de conexão e dificuldades de infraestrutura no que se refere ao acesso à internet, a OECD divulgou o seguinte diagnóstico sobre o Brasi: "Some countries have large absolute amounts of infrastructure, which is one indication of national capacity for receiving ICT-enabled offshored services. For example, China has more PCs than Germany and more Internet subscribers than the United States. Brazil, India and Russia each have about as many PCs as Canada or Italy, and Brazil and India have slightly fewer Internet subscribers than Canada. However, apart from China, these countries' broadband subscriber numbers are much lower, and broadband costs are much higher than in most OECD countries in all of them" (OECD, 2009, p. 32). 
lares conectados a depender da região do país. Há evidências, ainda, de que a desigualdade se acentua se forem consideradas as diferenças de velocidade de conexão entre regiões. Ou seja, mesmo que tenham disposição em pagar mais caro pelo serviço, não há oferta de serviço por parte das operadoras em determinadas localidades. Este diagnóstico acaba gerando um conjunto de críticas às empresas e ao próprio Estado. Este deveria fiscalizar e pressionar as prestadoras no sentido de garantir metas mais ambiciosas de universalização dos serviços e aumento da qualidade de conexão.

\section{A Anatel tem sido provocada a interferir nas} práticas de mercado adotadas por empresas de telefonia, dada a discrepância percebida, por exemplo, na oferta de velocidade de conexão e de preços (WIZIACK, 2010). Diante de tal cenário, os atritos do Governo com as operadoras têm aumentado e, a bem da verdade, não são recentes. Mais ainda, as divergências e cobranças não se restringem ao campo da oferta de acesso à internet (FERNANDES, 2011a).

Como vimos, a quantidade de telefones celulares no Brasil já chegou a mais de 227 milhões de linhas. No entanto, apenas 18,36\% (41,7 milhões) destas linhas são pós-pagas. 0 restante $(81,64 \%$, o que corresponde a 185,6 milhões) atende, de maneira geral, a um público de baixa renda ou que não faz uma assinatura regular por conta do alto custo das tarifas. No último ano, as empresas (sobretudo aquelas de telefonia móvel) têm sido acusadas pelos fornecedores de equipamentos de informática de diminuir os investimentos na melhoria dos serviços (OPERADORAS..., 2010). Como consequência, uma quantidade cada vez maior de clientes reclama de congestionamento no tráfego de dados ao tentarem navegar ou, simplesmente, enviar mensagens de texto. As empresas se defendem alegando que os preços altos se dão, em boa parte, por conta da elevada carga tributária embutida na oferta de serviços. Além disso, elas argumentam ainda que os altos custos relativos ao investimento em infraestrutura justificariam a diferença de preços entre regiões, uma vez que determinadas áreas mais remotas do país apenas podem ser alcanças por transporte aéreo ou fluvial. 0 que se verifica, no entanto, é que, mesmo em municípios da região metropolitana do Rio de Janeiro, os usuários são penalizados com 0 pagamento de tarifas bem mais altas do que aquelas testemunhadas na capital (WIZIACK, ${ }^{2010) .}$

\section{Governo, através do Ministério das}

Comunicações, tem se esforçado para pressionar as empresas a aceitarem metas mais ousadas no que se refere à formulação de um novo Plano Geral de Metas de Universalização (PGMU), mas a pressão, muitas vezes, acaba nos tribunais. Uma das últimas tensões se refere à resistência das empresas de telecomunicações ao Plano Nacional de Banda Larga (PNBL). De início, algumas delas chegaram a ameaçar contestar o PNBL na Justiça (TELES..., 2010). Após um intenso processo de negociação (e de concessões por parte do Governo), algumas das operadoras aderiram ao plano, que teve início na metade de 2011. 
A seguir, as características do PNBL são

detalhadas, examinando-se suas potencialidades e limites, a fim de verificar em que medida o projeto delineado pelo Governo Federal responde às demandas da sociedade (cidadãos e empresas) no contexto de produção e consumo de informações em suporte digital que marca o século XXI.

\section{Plano Nacional de}

\section{Banda Larga: características, potencialidades e problemas}

0 Plano Nacional de Banda Larga (PNBL) foi lançado oficialmente em maio de 2010. 0 objetivo é elevar 0 acesso à internet de 12 milhões para 40 milhões de domicílios em todas as regiões do país. A gestão do plano está sob a coordenação da empresa estatal Telebrás (Telecomunicações Brasileiras S.A), ao custo estimado de $\mathrm{R} \$ 12,8$ bilhões/US \$ 6,5 bilhões pelo período 2010-2014. No início, serão 100 cidades atendidas (ver mapa dos Estados contemplados), mas espera-se que, até 2014, todos os municípios brasileiros tenham disponível serviço de internet rápida. ${ }^{5}$

0 PNBL pode ser visto como um plano de inclusão digital. A discussão sobre a inclusão digital está presente na agenda das políticas públicas governamentais desde 1999, quando 0 Governo Federal lançou o Programa Sociedade da Informação, por meio do Decreto $\mathrm{n}^{0} 3.294 \mathrm{em}$ 15 de dezembro, que culminou na elaboração do

Mapa 1: Estados que terão as primeiras cidades contempladas com o PNBL 
chamado Livro Verde, em 2000 (TAKAHASHI, 2000). Depois, veio o lançamento do projeto Computadores para Todos (2005-2008), (QUEIROZ, 2008) cujo objetivo foi reduzir os preços das máquinas para facilitar 0 acesso aos computadores. 0 primeiro projeto perdeu os rumos e foi descontinuado na prática, uma vez que um governo com tendência político-ideológica distinta assumiu o poder em 2003 e decidiu modificar os rumos das iniciativas de inclusão digital; 0 segundo perdeu relevância, já que 0 próprio mercado se incumbiu de reduzir os preços.

0 diagnóstico que justifica 0 atual PNBL se refere ao fato de que o país está atrasado se comparado aos outros países chamados de "emergentes", com serviços caros, concentrados em poucas regiões e estados (Rio e São Paulo) e lentos, configurando um quadro de pouca agressividade política para reverter essa situação, como vimos no tópico anterior. Dados da Teleco (Inteligência em Telecomunicações) mostram que 0 mercado de banda larga no Brasil atual é altamente concentrado, dividido entre as operadoras 0i (30,5\%), Net (25,4\%), Telefônica (22,8\%), GVT ( $8,8 \%)$, CTBC $(1,7 \%)$ e outras $(10,8 \%)$ (RONCOLATO, 2011). Assim, o objetivo do governo brasileiro é massificar o uso de banda larga no país, principalmente entre as classes C, D e E. Portanto, descentralizar o acesso, baratear custos, expandir as formas de conexão e melhorar os serviços de internet no Brasil é o desafio do Plano Nacional de Banda Larga, anunciado pelo então presidente Luis Inácio Lula da Silva, e implementado pelo atual governo, sob a Presidência de Dilma Rousseff.

A intenção do governo é louvável já que o PNBL visa oferecer à população brasileira acesso à internet de alta velocidade a um baixo custo. A proposta parte da ideia de que 0 acesso à internet configura-se como um valor fundamental para o desenvolvimento social, econômico e cultural do país. ${ }^{6} 0$ acesso à internet deve ser pensado como um fator estratégico para o desenvolvimento da cultura digital no país. E como vimos, os brasileiros têm mostrado um grande potencial como produtor, distribuidor e consumidor de bens digitais. 0 PNBL, que está previsto no Plano Geral de Metas de Universalização (PGMU), aprovado em Junho de 2011, passou por modificações diversas desde que foi concebido, sendo um dos momentos mais tensos da negociação a posição inflexível da presidente Rousseff sobre o mínimo de velocidade oferecida, que passou de $600 \mathrm{Kbps}$ para $1 \mathrm{Mbps}$, ao preço de $\mathrm{R} \$ 35$ [US\$20,58] por mês.

Para se ter uma ideia, no Brasil, a banda larga tem menor penetração e é mais cara que a do Chile e da Argentina, por exemplo. Mas não existe no mundo nenhum plano como o PNBL 
brasileiro. Há iniciativas similares, mas não com o peso governamental como ocorre no caso brasileiro. De acordo com o portal do governo federal, os planos de banda larga equivalem ao brasileiro em termos de velocidade de conexão. Dados mostram que, entre os países com maior porcentagem da população que utiliza internet de alta velocidade, encontra-se em primeiro lugar a Coréia do Sul, 97\%, seguida de Suíça, 90\%, Noruega, 84\%, e Holanda, 83\%. 0s Estados Unidos estão em $15^{\circ}$ lugar e o Brasil em $53^{\circ}$, com 19\% (VERSIGNASSI; NOGUEIRA, 2010). 0s Gráficos 1 e 2 mostram os projetos de banda larga em alguns países em termos de velocidade, de investimento e de direitos adquirido pelos cidadãos. (BRASIL, 2011)
No Brasil, a proposta é de oferecer a preços baixos a velocidade de $1 \mathrm{Mbps}$ apenas para 2014. A premissa da atual política é correta: 0 governo precisa ser agressivo e garantir uma infraestrutura realmente nacional para fomentar algo que já está na cultura brasileira: a cultura digital. Mas o futuro não parece ser muito promissor.

Deve-se ressaltar que o PNBL é um plano de inclusão digital que passa pela expansão da infraestrutura da rede e da capacidade de transmissão de dados. Aqui se encontra um outro problema típico do caso brasileiro, concernente à diferença de velocidade contratada pelo usuário e aquela que é, efetivamente, entregue por parte

\section{Gráfico 1}

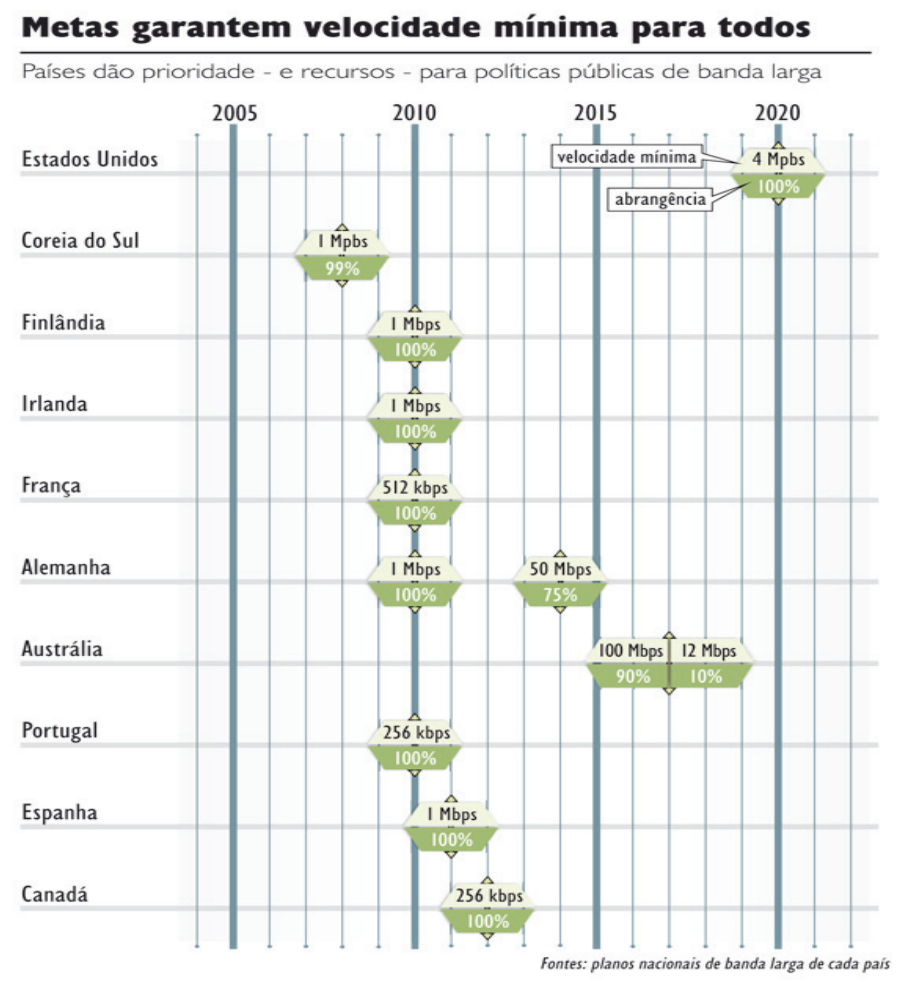




\section{Países investem em expansão}

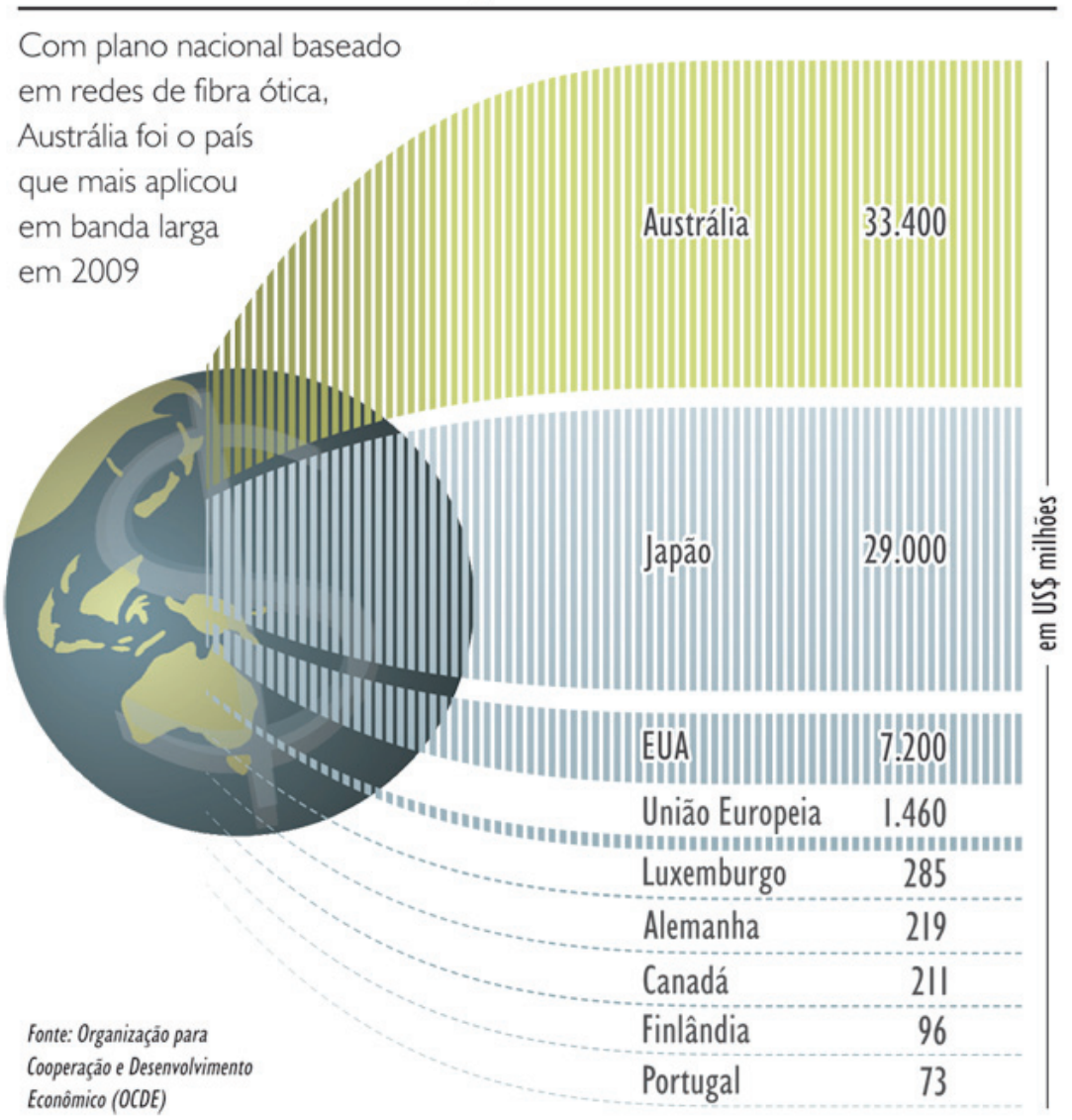

das empresas. Atualmente, as operadoras garantem

qualidade da internet será medida através de um oferecer, no mínimo, 10\% da velocidade contratada, software a ser instalado pelos consumidores no o que não parece razoável, uma vez que se está pagando a tarifa cheia. Ou seja, encontra-se, em tal aparelho em que faz uso do serviço. 0 software será desenvolvido pelas próprias operadoras e estará aspecto, mais um foco de tensão quanto à falta de obrigatoriamente disponível em seus portais na rede. critérios claros que exijam parâmetros aceitáveis de No entanto, especialistas argumentam que 0 custo conexão, mesmo quando os usuários estão dispostos final será muito maior do que o sugerido. Como a pagar (caro) pelo serviço. mostrou Fabio Rodrigues em seu blog, os usuários vão ter que pagar bem mais para garantir uma

0 governo determinou recentemente que os conexão de 1MBps, já que há diferentes abordagens provedores, ao serem contratados (estejam ou adotadas pelas concessionárias do serviço.

não integrados ao PNBL) devam garantir 60\% da velocidade contratada no primeiro ano de contrato, $70 \%$ no segundo e $80 \%$ a partir do terceiro. A taxas de habilitação. Enquanto na Sercomtel isso 
significa $\mathrm{R} \$ 50$ [US\$29,41] a mais na primeira mensalidade, na 0i o valor de $\mathrm{R} \$ 99$ [US\$ 58,23] foi dividido em 10 vezes - 0 que faz, nesse período, com que os $\mathrm{R} \$ 35$ [US\$20,58] virem $\mathrm{R} \$ 44,90$ [US\$ 26,41]. Já a Telefônica prevê uma cobrança de R $\$$ 150 [US\$ 88,23], também sob a forma de taxa de habilitação, mas utiliza 0 valor como uma forma de fidelização - 0 cliente só paga caso cancele 0 serviço antes de 0 contrato completar um ano. Como atua em São Paulo, onde há isenção de ICMS para banda larga 'popular', a assinatura é de $\mathrm{R} \$ 29,80$ [US\$ 17,52]. A própria empresa deixou claro, no entanto, que a oferta nos moldes do acordo se dará por meio da venda conjunta com telefonia fixa, ou seja, um pacote de $\mathrm{R} \$ 65$ [US $\$$ 38,23 - ainda que 'promocionalmente' o valor anunciado pela Telefônica R $\$ 57,30$ [US\$ 33,70]. Quem quiser comprar apenas acesso a internet deve fazê-lo através da Vivo, que já possuía oferta de R $\$ 29,90$ [US\$ 17,58] (GROSSMANN, 2011).

0 preço sai mais caro também porque a velocidade de 1 Mbps prevê um limite do tráfego de dados (download) inicial de 300Mb para acesso fixo e de $150 \mathrm{Mb}$ para acesso móvel ${ }^{7}$. Provavelmente, os usuários não vão conseguir atualizar programas que empregam quotidianamente, já que a quantidade de bits excederá as cotas permitidas. Para continuar utilizando o serviço, eles deverão pagar mais, ou reduzir a velocidade de acesso. Assim, o lobby das empresas de telecomunicações e das operadoras de internet que dominam 0 mercado no país está colocando limites muito concretos ao sucesso do empreendimento. Ouvir música, ver filmes, vídeos ou mesmo baixar e atualizar programas na máquina estão, nesse modelo, inviabilizados.

Ora, a vantagem para as operadoras em limitar a taxa de download se dá em, pelo menos, dois aspectos: 1) serão necessários menores investimentos em infraestrutura para viabilizar o serviço, uma vez que a quantidade de dados solicitados pelos usuários tende a diminuir à medida que eles percebem que se encontram perto de ultrapassar a barreira estabelecida; 2) sabendo da dificuldade dos usuários para acederem a determinados conteúdos, as empresas almejam incentivar seus clientes a mudarem de plano, pagando mais caro. Em outras palavras, os lucros das empresas apenas tendem a subir se as metas não forem mais ousadas.

\section{Para Mário Brandão, presidente da Associação} Brasileira de Centros de Inclusão Digital (ABCID), é possível comparar as limitações do PNBL com as mesmas dificuldades que a telefonia móvel enfrenta no Brasil.

Todos, no Brasil, temos acesso à telefonia celular? Aos meios sim; ao uso, não! Explico: o Brasil de 180 milhões de habitantes tem 200 
milhões de aparelhos celulares, o que é ótimo.

Mas desses 2/3 não efetuaram nenhuma ligação nos últimos seis meses. Isso demonstra que a população de baixa renda tem celular, mas não pode realizar ligações porque não tem créditos para isso (BRANDÃo, 2011).

Consequentemente, o Plano Nacional de Banda Larga, se assim se constituir, será um projeto que visa incluir, mas que, na realidade, exclui os já excluídos, dando a eles um falso sentimento de inclusão. A inclusão será de um cidadão "interagido" e não "interagente" (CASTELLS, 1996), como veremos mais adiante. Em outras palavras, o PNBL parece estar sendo pensado para um cidadão que checa e-mails, navega pouco na Web e que não usa as redes sociais, blogs ou o YouTube. Ora, esse usuário praticamente não existe mais hoje. Portanto, três pontos são bastante negativos em uma avaliação mais

aprofundada acerca do PNBL:

1. A garantia de oferecer apenas $60 \%$ da velocidade real do 1Mbps contratado. Leve-se em conta que 1Mbps já é muito pouco para o desempenho de tarefas diversas hoje em dia; 0 que dizer desta velocidade de acesso prevista para 2014. Além disso, a possibilidade de upload é ainda menor, $128 \mathrm{Kbps}$, o que dificulta 0 emprego das funcionalidades da chamada "Web 2.0";

\section{As empresas de telecomunicações serão} remuneradas de acordo com o volume do conteúdo acessado pelos usuários, mudando a lógica que vinga até então na rede brasileira. Adotar esta postura pode vir a quebrar o princípio básico da neutralidade da rede, já que o fluxo de dados será tratado de forma discriminada. Além disso, as operadores vão limitar

\section{Cidadãos de vários países já têm direito a internet banda larga}

Além das metas de velocidade, governos preocupam-se em assegurar o direito legal ao acesso

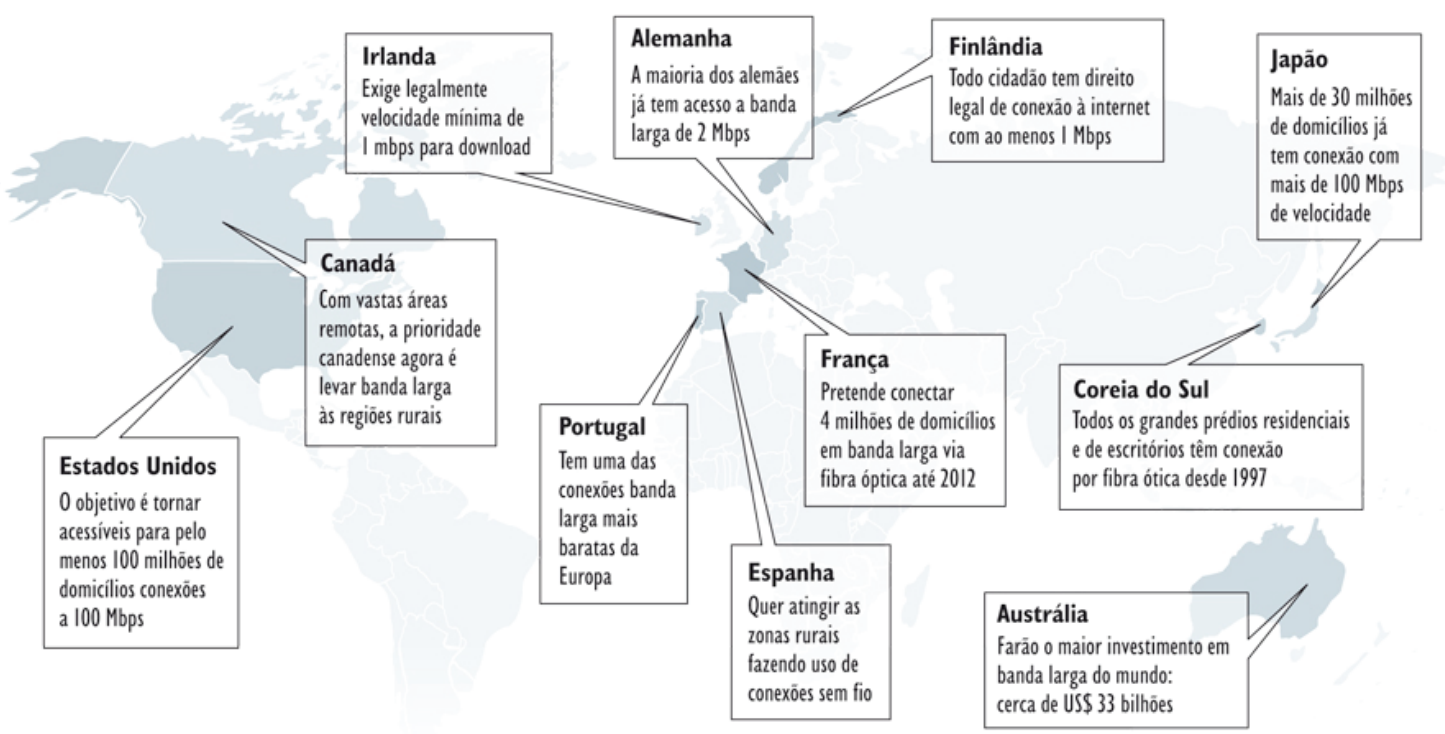


a quantidade de dados que o usuário pode baixar por mês (300Mb), o que é impensável para um uso minimamente razoável da internet e;

3. Estima-se que, devido aos limites de download e upload, os custos finais para os usuários serão muito maiores dos que os $\mathrm{R} \$ 35,00$ [US $\$ 20,58$ ] previstos no PNBL. Considere-se, por exemplo, a necessidade de aquisição, separadamente, de um modem para que 0 acesso sem fio se torne viável.

Nesse sentido, há indícios de que o PNBL pode fracassar. Marcelo Branco, coordenador da campanha digital da atual presidente Dilma Rousseff durante as eleições de 2010, em recente depoimento, pediu uma maior atuação dos Estados brasileiros a fim de melhorar as negociações com as Teles. Para Branco, os governos estaduais e municipais são os que mais gastam com serviço de telecomunicações e acesso à internet. No entanto, tais instituições não estariam exercendo o poder de pressão que têm. Para Branco (2011):

0 governo do estado tem investido muito dinheiro com serviços de Telecomunicações. [...] Se uma empresa tem uma conta gigantesca com um fornecedor, ela tem o poder de barganhar algumas vantagens em uma negociação. Com certeza 0 maior cliente de Telecom do Rio Grande do Sul é o governo do estado. Então, qual é o papel do governo Tarso [Tarso Genro, Governador do Estado do Rio Grande do Sul] nessa discussão?
Conforme visto, o objetivo do PNBL é prover acesso de boa qualidade e com uma velocidade minimamente aceitável para universalizar o serviço e tentar atenuar as disparidades regionais. Dificilmente, todavia, a meta será alcançada se forem mantidos os termos atuais. Para funcionar e atingir seus objetivos, 0 PNBL deveria ser pensado dentro de uma visão estratégica de garantia das liberdades individuais, da privacidade, do anonimato e de efetiva participação e uso da internet. $\mathrm{Na}$ configuração proposta, só haverá cidadãos "interagidos", ou seja, com limitada autonomia para produzir e consumir conteúdos. Sabe-se que há uma relação direta entre 0 aumento do PIB e a velocidade de acesso e universalização dos serviços de internet. Segundo dados do Banco Mundial, a cada aumento de $10 \%$ nos serviços de banda larga há um incremento de 1,4\% no PIB (VERSIGNASSI; NOGUEIRA, 2010). Como está projetado pelo Plano do Governo, o acesso será caro, com poucas opções de uso para os cidadãos e com o grave precedente de poder quebrar 0 paradigma da neutralidade da rede. 0 ponto a seguir explora um pouco mais essa questão.

\subsection{Neutralidade da Rede: interfaces com 0 PNBL}

Neutralidade de Rede é o princípio orientador que preserva a Internet livre e aberta. A Neutralidade de Rede significa que os prestadores de serviços de Internet não podem discriminar a transmissão de diferentes tipos de conteúdo e aplicativos online. [...] A Neutralidade de Rede é a razão pela qual a Internet tem impul- 
sionado a inovação econômica, a participação democrática e a liberdade de expressão online. Ela protege o direito do consumidor de usar qualquer equipamento, conteúdo, aplicação ou serviço sem a interferência do operador de rede. Com a Neutralidade de Rede, 0 único trabalho da conexão é transportar dados - e não escolher quais dados privilegiar com maior qualidade de serviço. ${ }^{8}$ (SAVE THE INTERNET).

É necessário garantir não só largura de banda, preço, inclusão e equilíbrio regional. Inserir no mundo digital mais 40 milhões de domicílios é uma excelente aposta e é fato que o governo brasileiro não poderá executar um projeto desse porte sem a participação das Teles. No entanto, a parceria deve ser efetivada com vistas a garantir um bom preço, a velocidade acordada e a neutralidade da rede. Da forma como está, o PNBL acaba se convertendo em uma ameaça ao princípio fundador da liberdade na internet: a sua neutralidade. Se tal princípio for rompido, a rede se transformará em uma espécie de TV à cabo por computadores, onde alguns canais (pacotes) são acessados através de pagamento específico. É fundamental, desta forma, garantir que a redução de desigualdades de acesso à internet pelo PNBL não tenha como contrapartida a quebra da neutralidade da rede.

Para Marcelo Branco:

0 principal erro desse acordo é a tentativa de fazer com que as Teles recebam dinheiro pelo volume de conteúdos acessados pelo usuário. Até hoje, dentro da lógica de funcionamento da internet, quem pode cobrar pelos conteúdos na rede é o gerador de conteúdo e não as operadoras. A partir do acordo firmado com o Ministério das Comunicações, as Teles, além de ganharem pela largura da banda que oferecem, pela velocidade de transmissão, passarão a limitar a quantidade de conteúdo que 0 usuário pode baixar durante 0 mês (BRANC0, 2011).

Marcelo Branco continua 0 argumento: A neutralidade na rede é a nossa principal luta nesse momento. Nos Estados Unidos, a FCC [Federal Communications Comission], que é a Anatel deles, sofre também uma forte pressão para quebrar a neutralidade da internet. Existe um lobby das operadoras de telecomunicações privadas para se quebrar a neutralidade. Há uma preocupação no Brasil de que a Anatel passe a regulamentar a internet. 0 comitê gestor da internet BRASIL é um exemplo de gestão para outros países e para a governança internacional da rede. Quem gerencia a internet no Brasil é 0 Comitê Gestor, um órgão muito mais democrático, que é uma referência para outros países na gestão democrática da internet e modelo para a governança mundial da rede. 0 comitê gestor conta com a participação dos empresários

8 "Net Neutrality is the guiding principle that preserves the free and open Internet. Net Neutrality means that Internet service providers may not discriminate between different kinds of content and applications online. It guarantees a level playing field for all Web sites and Internet technologies. Net Neutrality is the reason the Internet has driven economic innovation, democratic participation and free speech online. It protects the consumer's right to use any equipment, content, application or service without interference from the network provider. With Net Neutrality, the network's only job is to move data - not to choose which data to privilege with higher quality service". 
privados, da sociedade civil, dos governos e da academia. Seria inadmissível que um órgão como a Anatel, que representa apenas um dos setores, passasse a regulamentar a internet no Brasil (BRANC0, 2011).

A dimensão do debate sobre a neutralidade da rede é espacial e política. Ela pode ser entendida como uma isonomia topológica dos nós da rede que mantêm todas as informações em igual grau de acessibilidade, independente do tipo (dado, texto, som, imagem) ou aplicativo. Assim, pode-se dizer que o princípio de neutralidade se baseia em uma arquitetura da rede que a constrói como um espaço neutro (politicamente aberto), independente do tipo de conteúdo e aplicativo produzidos, distribuídos ou consumidos. Assim, o espaço constituído pela neutralidade da rede diz que os "lugares" de acesso são iguais em termos de acessibilidade. Para garantir a neutralidade, os provedores de acesso, que oferecem as vias para movimentação por esse "espaço", não podem instituir zonas de navegação, bloquear ou limitar, por meio de cobranças ou de redução de velocidade do acesso aos lugares (sites, aplicativos...). Esses lugares, sim, podem cobrar para serem usados, por conta de seu conteúdo, mas 0 acesso a eles não pode ser diferente de uma navegação por outros lugares da rede.

Para usarmos uma analogia com as cidades, é como se o governo permitisse a ida a alguns lugares e não a outros; é como se, para se deslocar, o cidadão devesse pagar por sua escolha (se anda em uma rua ou avenida, por exemplo). Em alguns casos, isso até acontece, mas sob marcos jurídicos muito bem constituídos, como pedágios para automóveis, por exemplo. Mas, mesmo aqui, cobrase pelo serviço (a estrada cuidada). Portanto, 0 governo brasileiro (bem como todos governos) deve garantir que o espaço seja neutro, público, em seu acesso aos lugares que o constituem. Um provedor não pode, desta maneira, cobrar mais para o usuário acessar o YouTube a uma determinada velocidade, por exemplo, sobre alegação que os vídeos usam mais capacidade de banda da rede. Isso acabaria com a dinâmica democrática, transversal e conversacional que caracteriza a comunicação digital. Essa é a principal garantia de que a internet continuará sendo um "espaço" sem restrições para inovações técnicas e para o desenvolvimento cultural, social, político e econômico.

Vários países vêm adotando leis para garantir a neutralidade da rede. Recentemente, 0 governo dos Estados Unidos enviou regras - ainda tímidas, mas já é um avanço - à FCC (Federal Communications Commission) que visam garantir essa neutralidade (transparência das práticas por parte dos provedores, proibição de bloqueio de conteúdos e aplicativos e de discriminação de conteúdo do tráfego). Segundo Bruno Magrani:

Governos e entidades reguladoras ao redor do mundo, despertados pelos cada vez mais frequentes exemplos de afronta à neutralidade de rede tem iniciado um processo de discussão 
e implementação das primeiras normas sobre neutralidade de rede. Seguindo a liderança do Chile, que em 2010 aprovou a primeira lei sobre neutralidade de rede do mundo, Colômbia recentemente adotou norma em seu plano nacional de desenvolvimento para impedir práticas de discriminação de informações. No âmbito da União Europeia, Holanda foi a pioneira na adoção de norma específica. Um quadro comparativo das principais regulamentações e propostas de regulamentação de neutralidade de rede em alguns países da América Latina pode ser visto abaixo. A coloração indica a influência de uma lei sobre as leis de outros países, assim vemos que a lei chilena tem uma fortíssima influência sobre o projeto de lei argentino e sobre a lei colombiana de neutralidade. Brasil e México por sua vez tem discutido abordagens distintas da Chilena (MAGRANI, 2011).

Jomar Silva (2010), em artigo publicado no blog Trezentos, afirma que o Comitê Gestor da Internet no Brasil (CGI.br) aprovou e publicou, em 2009, uma resolução onde define os "Princípios para a Governança e uso da Internet no Brasil". Particularmente sobre a neutralidade, Silva destaca o ponto 6 do documento, onde se pode ler que "filtragem ou privilégios de tráfego devem respeitar apenas critérios técnicos e éticos, não sendo admissíveis motivos políticos, comerciais, religiosos, culturais, ou qualquer outra forma de discriminação ou favorecimento". (CGI.BR, 2009) A diretriz toca na questão, mas ainda parece muita ampla e imprecisa.

No Brasil, o principal instrumento de discussão sobre a regulação da internet é o Marco Civil da
Internet, ${ }^{9}$ projeto de lei que define direitos e responsabilidades no uso, elaborado a partir de consulta pública e discussão organizadas pelo Ministério da Justiça. Atualmente, o projeto encontra-se em tramitação para ser aprovado ou rejeitado. A proposta de Marco Civil trata da questão da neutralidade da rede em vários artigos, prevendo a garantia da forma isonômica no tratamento dos dados, sem distinção de conteúdo, origem ou destino. Veta-se a discriminação de conteúdos e aplicativos. Há brechas, todavia, para a quebra da neutralidade de rede, já que o Marco Civil prevê que pode haver tal quebra se estiver clara a "necessidade para a prestação adequada do serviço". Mas, observe-se, o princípio geral de proteção a usuário está lá. Recentemente, o Sindicato das Empresas Operadores de Serviços de Telecomunicações (SindiTelebrasil) e a Anatel tentam flexibilizar a brecha deixada no Marco Civil. Agora, com o PNBL, e com o aval do Governo brasileiro, a questão fica ainda mais aguda. 0 futuro será decidido nos próximos meses. Como afirma Magrani (2011):

0 marco civil estabelecerá uma regra geral sobre neutralidade impedindo qualquer tipo de tratamento diferenciado para a informação, salvo paras as hipóteses em que as eventuais discriminações ou degradações decorram de requisitos técnicos necessários à prestação adequada dos serviços. [...] 0 regulamento prevê uma regra geral de não discriminação 
e vai além, deixando explícito a proibição ao bloqueio de conteúdo e aplicativos.

\subsection{Inclusão Digital: seria o PNBL uma solução plausível?}

De acordo com o que pode ser percebido, discutir inclusão digital é um assunto espinhoso, que demanda a elaboração de políticas que compreendam 0 acesso às novas tecnologias de comunicação e informação como elementos de inclusão social em sentido amplo.

A inclusão digital não é alcançada apenas quando se dá computadores ou acesso à internet, mas quando o indivíduo é colocado em um processo mais amplo de exercício pleno de sua cidadania. A inclusão digital deve, consequentemente, ser pensada de forma complexa, a partir do enriquecimento de quatro capitais básicos: os capitais social, cultural, intelectual e técnico (LÉVY, 1998; LEMOS, 2007). 0 capital social é aquele que valoriza a dimensão identitária e comunitária, os laços sociais e a ação política. 0 capital cultural é 0 que remete à história e aos bens simbólicos de um grupo social, ao seu passado, às suas conquistas, à sua arte. Já 0 capital técnico é 0 da potência da ação e da comunicação. É ele que permite que um grupo social ou um indivíduo possa agir sobre o mundo e se comunicar de forma livre e autônoma. 0 capital intelectual é 0 da formação da pessoa, do crescimento intelectual individual com a aprendizagem; evidencia a troca de saberes e 0 acúmulo de experiências.
Incluir é, assim, em qualquer área e em todos os sentidos, possibilitar o crescimento dos quatro capitais. Incluir, na e para a sociedade da informação, significa usar as tecnologias de informação e comunicação como meios de expandir esses capitais. Garantir qualidade de conexão, preços baixos e neutralidade da rede é a única maneira pela qual o Plano Nacional de Banda Larga poderá potencializar o desenvolvimento dos quatro capitais mencionados. 0 PNBL é um projeto de oferecimento de acesso barato (ou seja, age nas dimensões técnica e econômica), mas suas implicações, como vimos, são políticas e, em um grau mais amplo, socioculturais (atuando nos outros dois capitais). 0 PNBL visa dar oportunidades a uma grande parcela da população excluída do uso e dos benefícios da sociedade da informação a partir de uma melhoria das condições de acesso à internet.

Muitos do que usam de forma compulsória essas tecnologias são, como diz o sociólogo espanhol Manuel Castells (1996), "interagidos" e não "interagentes"; ou seja, eles utilizam de uma forma muito rudimentar os dispositivos e as redes eletrônicas, não alcançando as condições ideais a fim de tirar proveito de todos os benefícios culturais, sociais e econômicos que as mídias digitais oferecem. Com 0 atual PNBL, a falta de garantias de velocidade mínima, 0 limite da quantidade de dados para download, a incerteza relacionada ao preço variável e 0 fantasma da quebra da neutralidade da rede podem levar a uma inclusão de apenas "interagidos". 


\section{Conclusões}

Os detalhes sobre o PNBL brasileiro foram apresentados, deixando-se claro seus limites. A intenção do trabalho foi apontar em que medida o projeto delineado pelo Governo Federal pode responder ou não às demandas da sociedade. As reviravoltas que o PNBL sofreu nos últimos meses foram discutidas, bem como as tensões e os interesses dos agentes envolvidos no processo, abrindo-se espaço para a abordagem acerca de suas consequências sociais e políticas.

Pode-se dizer que a última década do século XX transformou profundamente o cenário das telecomunicações no Brasil. Pelo menos dois grandes acontecimentos modificaram a realidade do mercado nacional: (1) o fim do monopólio das telecomunicações e (2) a venda de empresas públicas. Nesta nova realidade, os serviços de telefonia e de acesso à internet passam, fundamentalmente, a serem oferecidos pela iniciativa privada, inclusive por empresas multinacionais; as operações são fiscalizadas por agência reguladora, a Anatel.

Se a privatização serviu como justificativa para responder às demandas por abertura comercial e de alinhamento com a economia globalizada, é plausível afirmar que a atuação dos agentes

do Estado brasileiro ainda não parece ter surtido 0 efeito desejado no que se refere à universalização e barateamento na oferta de serviços de telecomunicações. Seja por pressão das empresas, seja por pressão de agentes do campo político (deputados e senadores que são financiados por empresas de telecomunicações e de radiodifusão, por exemplo), há inúmeras resistências a controle ou regulação mais estritos no campo das comunicações no Brasil.

Ainda que, em áreas diversas, as empresas se submetam a processos rigorosos de concorrência e fiscalização uma vez que recebem concessões públicas, no campo da radiodifusão isso ainda não acontece de maneira semelhante. Nas telecomunicações, 0 embate entre governo e empresas se localiza, em boa parte, nas tentativas de universalização dos serviços. A iniciativa privada tem interesse apenas em investir nas áreas mais lucrativas, deixando de atender a regiões distantes. Desta forma, não há dúvidas acerca do potencial de expansão dos serviços de telecomunicações no Brasil (há clientes ciosos de conexão); entretanto, a realidade de mercado não parece favorável à concorrência, já que há cidades do interior do Brasil que contam com apenas uma operadora de telefonia móvel. ${ }^{10}$ 
0 cenário brasileiro fica ainda menos animador ao se perceber que 0 Governo abre mão de metas mais ambiciosas de universalização das telecomunicações ou que não utiliza os fundos reservados para expandir a infraestrutura por conta do contingenciamento de recursos. De acordo com matéria da Folha0nline, por exemplo, "Os fundos setoriais de telecomunicações arrecadaram $\mathrm{R} \$ 48,5$ bilhões [US $\$ 28,52$ bilhões] em dez anos, mas apenas $\mathrm{R} \$ 2,6$ bilhões [US $\$$ 1,52 bilhões], ou seja, $5,4 \%$ do total dos recursos, foi usado para a sua finalidade original, como expansão dos serviços de telecomunicações, inclusive no meio rural". (FERNANDES, 2011b) Desta forma, as políticas de governo precisam se preocupar não apenas em desonerar a cadeia produtiva envolvida no combate à exclusão digital (menos impostos para máquinas e contratação de serviços). Estão em pauta questões relacionadas à privacidade e à segurança, itens fundamentais para que a boa qualidade do acesso seja possível.

Considera-se, então, que o PNBL pode ser um excelente projeto, mas precisa, rapidamente, de ajustes, sob a pena de fracassar antes mesmo de chegar a ser implementado, seja pela ineficiência dos poderes públicos, seja pela força dos lobbies, ou seja, simplesmente, pela dinâmica do mercado. 0 Plano pode ser um bom indutor da concorrência para melhoria dos serviços e barateamento dos custos, mas o governo não pode permitir velocidades menores, preços maiores ou quebra da neutralidade da rede. Deve-se garantir 0 acesso a uma internet de boa qualidade, neutra e rápida.
A iniciativa é louvável, mas o PNBL deve sustentar o binômio (a) redução de desigualdades de acesso (inclusão digital), e (b) neutralidade da rede. Só assim ele poderá ser um excelente instrumento para garantir a inovação, o crescimento econômico, a pluralidade informacional, o engajamento político, a liberdade e o crescimento cultural.

0 desafio maior da inclusão cidadã no universo da cultura digital é fazer com que os indivíduos possam produzir conteúdos próprios e distribuílos livremente, mantendo-se senhor dos seus dados pessoais, garantindo-se a neutralidade topológica da rede, a privacidade e 0 anonimato. Tanto quando o capital técnico, os projetos de inclusão digital devem fazer crescer os capitais social, intelectual e cultural. A inclusão pressupõe autonomia, liberdade e crítica. Para tanto o Brasil deve, nos próximos meses, responder à seguinte pergunta: como ampliar 0 acesso de toda a população brasileira, independente de região do país à banda larga de qualidade à internet, tendo como base um plano que não deixe os cidadãos reféns das operadoras, sem gargalos de conexão, com baixos preços e mantendo-se a neutralidade da rede?

\section{Referências}

AMATO, Fábio. Combo do plano de banda larga sairá a $\mathrm{R} \$ 65$ ou $\mathrm{R} \$ 69,90$, diz governo. 2011. Disponível em: < http://g1.globo.com/tecnologia/noticia/2011/07/ combo-do-plano-de-banda-larga-saira-r-65-ou-r-6990diz-governo.html>. Acesso em: 24 nov. 2011.

ANATEL - Agência Nacional de Telecomunicações. 
Relatório Anual 2001. disponível em: < http://www. anatel.gov.br/Portal/verificaDocumentos/documento.asp? numeroPublicaca $=50017 \&$ assuntoPublicaca $0=$ Relat $\%$ F3rio\%20Anual\%20da\%20Anatel\%202001\&caminhoRel= null\&filtro=1\&documentoPath = biblioteca/publicacao/ relatorio_anatel_2001.pdf. Acesso em: 09 nov. 2011.

BRANCO, Marcelo D'Elia. Marcelo Branco: Lobby das teles quer fim da neutralidade na rede. Entrevistador: Instituto Humanitas Unisinos. 2011. Disponível em: $<$ http://www.viomundo.com.br/entrevistas/marcelobranco-lobby-poderoso-das-teles-quer-acabar-comneutralidade-da-rede.html>. Acesso em: 09 nov. 2011.

BRANDÃO, Mário. Tentativas de regulamentar a internet e o lento processo de democratização da rede: Entrevista especial com Mário Brandão. 2011. Disponível em: < http://goo.gl/WS14Z>. Acesso em: 09 nov. 2011.

BRASIL. Senado Federal. Banda larga no mundo. Jornal do Senado. Brasília, 15 fev. 2011. Em discussão. Disponível em: < http://www.senado.gov.br/noticias/ Jornal/emdiscussao/banda-larga/banda-larga-nomundo.aspx> . Acesso em: 14 nov. 2011.

BRASIL tem 40 milhões de linhas fixas. 2007. Disponível em: < http://info.abril.com.br/aberto/ infonews/112007/07112007-11.shl>. Acesso em: 09 nov. 2011.

BRASIL se aproxima de 230 milhões de linhas de celular. 2011. Disponível em: < http://wwwl.folha.uol.com.br/ mercado/992891-brasil-se-aproxima-de-230-milhoes-delinhas-de-celular.shtml>. Acesso em: 09 nov. 2011.

BRASILEIROS com acesso à internet já são 58,6 milhões. 2011. Disponível em: < http://wwwl.folha.uol. com.br/tec/940381-brasileiros-com-acesso-a-internetja-sao-586-milhoes.shtml> . Acesso em: 09 nov. 2011.

BRASILEIROS são os que mais assistem vídeos e TV pela internet, diz pesquisa. 2011. Disponível em: < http://g1.globo.com/tecnologia/noticia/2011/06/ brasileiros-sao-os-que-mais-assistem-videos-e-tv-pela- internet-diz-pesquisa.html>. Acesso em: 09 nov. 2011.

BRASILEIROS são os que mais usam as redes sociais no local de trabalho.[2011]. Disponível em: < http:// idgnow.uol.com.br/internet/2010/10/15/brasileirossao-os-que-mais-usam-as-redes-sociais-no-local-detrabalho/>. Acesso em: 09 nov. 2011.

CASTELLS, Manuel. The Rise of the Network Society. Cambridge, MA, Oxford, UK: Blackwell Publishers, 1996. (The information age: economy, society and culture, v. 1) CGI.BR - Comitê Gestor da Internet no Brasil.

Resolução n. 3, de 2009. Princípios para a governança e uso da internet. Disponível em: <: http://www.cgi.br/ regulamentacao/

resolucao2009-003.htm >. Acesso em: 29 maio 2012.

COSTA, Leonardo. Comunicação, novas tecnologias e inclusão digital - uma análise dos projetos realizados na Bahia. Dissertação de Mestrado. Universidade Federal da Bahia. Salvador, 2007.

CRIANÇAS brasileiras são as mais jovens a entrar em redes sociais, aponta pesquisa. 2011. Disponível em: < http://tecnologia.uol.com.br/ultimas-noticias/ redacao/2011/10/25/com-media-de-9-anos-brasileirossao-os-mais-jovens-no-mundo-a-entrar-nas-redessociais.jhtm>. Acesso em: 09 nov. 2011.

CRUZ, Renato. Banda larga popular nos EUA. 2011. Disponível em: < http://blogs.estadao.com.br/renatocruz/banda-larga-popular-nos-eua/. Acesso em: 14 nov. 2011.

ESTUD0 revela que 55\% dos brasileiros acessam sites de pornografia. [2011]. Disponível em: < http://idgnow.uol. com.br/internet/2008/02/13/estudo-revela-que-55-dosbrasileiros-acessam-sites-de-pornografia/> . Acesso em: 09 nov. 2011

FERNANDES, Sofia. Anatel aprova telefone popular a $\mathrm{R} \$$ 13,80. 2011a. Disponível em: < http://wwwl.folha.uol. com.br/mercado/924732-anatel-aprova-telefone-populara-r-1380.shtml> . Acesso em: 09 nov. 2011. 
Governo gastou só 5,4\% dos fundos setoriais com telecomunicações. 2011b. Disponível em: < http://wwwl.folha.uol.com.br/mercado/945226governo-gastou-so-54-dos-fundos-setoriais-comtelecomunicacoes.shtml>. Acesso em:

FIRJAN. Quanto custa o acesso à internet para as empresas no Brasil. Rio de Janeiro, 2011. (Estudos para o desenvolvimento do Estado do Rio de Janeiro, n. 7). Disponível em: < http://www.firjan.org.br/lumis/ portal/file/fileDownload.jsp?fileId = 2C908CEC2F01DD5 A012F225AE55B053C > . Acesso em: 09 nov. 2011.

GROSSMANN, Luis. Banda larga popular: custo fica acima do negociado entre teles e governo. 2011. Disponível em: < http://convergenciadigital.uol.com.br/ cgi/cgilua.exe/sys/start.htm?infoid $=27906 \&$ sid $=14>$. Acesso em: 06 out. 2011.

IBGE. Instituto Brasileiro de Geografia e estatística.

PNAD 2009: rendimento e número de trabalhadores com carteira assinada sobem e desocupação aumenta. Rio de Janeiro, 2010. Disponível em: < http://www.ibge. gov.br/home/presidencia/noticias/noticia_visualiza.

php?id_noticia $=1708>$. Acesso em: 09 nov. 2011.

INTERNAUTAS ativos chegam a 36,9 milhões no Brasil em janeiro de 2010. 2010. Disponível em: < http://wwwl.folha.uol.com.br/folha/informatica/ ult124u701238.shtml>. Acesso em: 09 nov. 2011.

JAMBEIR0, Othon et al.. Tempos de Vargas - 0 rádio e o controle da informação. Salvador: EDUFBA, $2004.194 \mathrm{p}$.

LEMOS, André. (Ed.). Cidade Digital. Portais, inclusão e redes no Brasil. Salvador: EDUFBA, 2007.

\section{LÉVY, Pierre. A inteligência coletiva. Por uma} antropologia do ciberespaço. São Paulo: Loyola, 1998.

MAGRANI, Bruno. Novos desenvolvimentos sobre a regulação da neutralidade de rede. 2011. Disponível em: < http://observatoriodainternet.br/novos- desenvolvimentos-sobre-a-regulacao-da-neutralidade-derede>. Acesso em: 05 out. 2011.

OECD - Organisation for Economic Co-operation and Development. Broadband and the Economy. Ministerial background report prepared for the OECD Ministerial Meeting on the Future of the Internet Economy, Seoul, 2009.

OPERADORAS de telefonia reduzem investimentos em 40\% no $1^{0}$ semestre. 2010. Disponível em: < http://wwwl. folha.uol.com.br/mercado/821929-operadoras-de-telefoniareduzem-investimentos-em-40-no-1-semestre.shtml> . Acesso em: 09 nov. 2011.

QUEIROZ, Luiz. Mercado de PCs continua crescendo após incentivos do governo. 2008. Disponível em: < http://www.computadorparatodos.gov.br/noticias/mercadode-pcs-continua-crescendo-apos-incentivos-do-governo $>$. Acesso em: 09 nov. 2011.

RAMOS, Murilo César. Às margens da estrada do futuro: comunicações, políticas e tecnologias. Brasília: UnB, 2000.

RONCOLATO, Murilo. Qualidade da banda larga sob consulta. 2011. Disponível em: < http://blogs.estadao.com. br/link/qualidade-da-banda-larga-sob-consulta/ > . Acesso em: 17 set. 2011.

SILVA, Jomar. 0 que é neutralidade da rede e porque você precisa se preocupar com isso. 2011. Disponível em: <http://www.trezentos.blog.br/?p=6465>. Acesso em: 09 nov. 2011.

\section{SAVE THE INTERNET. What is Net Neutrality?}

Disponível em: http://bit.ly/2xwFeo. Acesso em: 09 nov. 2011.

SUNDFELD, Carlos Ari. A regulação das telecomunicações: papel atual e tendências futuras. Revista Eletrônica de Direito Adminsitrativo Econômico. Salvador, Instituto Brasileiro de Direito Público, nº 8, nov./dez. Disponível em: http://www.direitodoestado.com/revista/REDAE-8NOVEMBR0-2006-CARLOS\%20ARI\%20SUNDFELD.pdf. Acesso em: 09 nov. 2011. 
SWISS Lead in Speed: Comparing Global Internet Connections. 2011. Disponível em: < http://blog. nielsen.com/nielsenwire/global/swiss-lead-in-speedcomparing-global-internet-connections/> . Acesso em: 09 nov. 2011.

TAKAHASHI, Tadao. (Org.). Sociedade da informação no Brasil: livro verde. Brasília: MCT, 2000. Disponível em: < http://www.mct.gov.br/upd_blob/0004/4795. pdf > . Acesso em: 09 nov. 2011.

TELES devem contestar Plano Nacional de Banda Larga. 2010. Disponível em: < http://wwwl.folha.uol. com.br/folha/dinheiro/ult91u735085.shtml > . Acesso em: 09 nov. 2011.

TEMPO do brasileiro na internet aumenta em mais de 3 horas em um ano. 2007. Disponível em: < http:// wwwl.folha.uol.com.br/folha/informatica/ult124u21706. shtml > . Acesso em: nov. 2011.

TOZZETO, Cláudia. Brasileiros são os que navegam mais tempo na internet. 2010. disponível em: < http://tecnologia.ig.com.br/noticia/2010/06/15/brasileiro $\mathrm{s}+\mathrm{sa} 0+\mathrm{os}+$ que + navegam + mais + tempo + na + inter net+9513651.html>. Acesso em: 09 nov. 2011.

VERSIGNASSI, Alexandre; NOGUEIRA, Salvador. Enlarge your PIB: banda larga faz a economia crescer. 2010. Disponível em: < http://superabril.com.br/ tecnologia/enlarge-your-pib-banda-larga-faz-economiacrescer-552080.shtml> . Acesso em: 17 nov. 2011.

WIZIACK, Júlio. Anatel estuda interferir em preços de banda larga após sinais de abusos. 2010. Disponível em: $<$ http://wwwl.folha.uol.com.br/folha/informatica/ ult124u711793.shtml> . Acesso em: 09 nov. 2011. 


\section{The Brazilian National Broadband} Plan: A reflection on its limits and socio-political effects

\section{Abstract}

The chapter examines the limits and the sociopolitical effects of the Brazilian National Broadband Plan (PNBL). The discussion considers the main transformations witnessed in the telecommunications landscape in Brazil during the second half of the twentieth century. On the one hand, the end of state monopoly on telecommunications services and the provision of such services by the private sector called for greater investments in infrastructure. On the other hand, the Brazilian regulatory agencies have failed, for example, in lowering prices and promoting competition in the sector. The PNBL was launched in order to deal with these difficulties. The Plan, however, has at least three important problems: (1) the low-speed connection offered to users, (2) the unattractive prices, and (3) the lack of reflection on issues such as net neutrality. The text argues that only taking into consideration such questions the Plan will ensure innovation, economic growth, diversity and freedom of informational access.

\section{Keywords}

Internet. Public Policies. Brazilian National Broadband Plan. Digital Divide. Net Neutrality.

\section{El Plan Nacional de Banda Ancha Brasileño: un estudio de sus límites y efectos sociales y políticos}

\section{Resumen}

El artículo examina los límites y los posibles efectos sociales y políticos del Plan Nacional de Banda Ancha. La discusión considera las transformaciones presentadas en el escenario de las telecomunicaciones brasileñas a lo largo de la segunda mitad del siglo XX. Por un lado, el fin del monopolio estatal de las telecomunicaciones y la venta de empresas publicas al sector privado trajeron mayores inversión en infraestructura. Por otro lado, la actuación de los agentes del Estado brasileño aún no parece tener surtido el efecto deseado en lo que se refiere a la universalización y la diminución del precio en la oferta de servicios de telecomunicaciones. El Plan fue lanzado con el objetivo de combatir tales dificultades. El proyecto, sin embargo, peca en lo que se refiere (1) a la baja velocidad de conexión que se ofrecerá a los usuarios; (2) a los precios poco atractivos; y (3) a la ausencia de reflexión acerca de la importancia de la neutralidad de la red. Se defiende que solo al complacer tales aspectos el Plan podrá garantizar innovación, crecimiento económico, pluralidad de información y libertad de acceso.

\section{Palabras clave}

Internet. Políticas Públicas. Plan Nacional de Banda Ancha Brasileño. Brecha Digital. Neutralidad de la red. 


\section{Expediente}

A revista E-Compós é a publicação científica em formato eletrônico da Associação Nacional dos Programas de Pós-Graduação em Comunicação (Compós). Lançada em 2004, tem como principal finalidade difundir a produção acadêmica de pesquisadores da área de Comunicação, inseridos em instituições do Brasil e do exterior.
E-COMPÓS I www.e-compos.org.br I E-ISSN 1808-2599

Revista da Associação Nacional dos Programas

de Pós-Graduação em Comunicação.

Brasília, v.15, n.1, jan./abr. 2012.

A identificação das edições, a partir de 2008

passa a ser volume anual com três números.

\section{CONSELHO EDITORIAL}

Afonso Albuquerque, Universidade Federal Fluminense, Brasil Alberto Carlos Augusto Klein, Universidade Estadual de Londrina, Brasil Álvaro Larangeira, Universidade Tuiuti do Paraná, Brasil Ana Carolina Damboriarena Escosteguy, Pontifícia Universidade Católica do Rio Grande do Sul, Brasil

Ana Gruszynski, Universidade Federal do Rio Grande do Sul, Brasil Ana Silvia Lopes Davi Médola, Universidade Estadual Paulista, Brasil André Luiz Martins Lemos, Universidade Federal da Bahia, Brasil Ângela Freire Prysthon, Universidade Federal de Pernambuco, Brasil Angela Cristina Salgueiro Marques, Faculdade Cásper Líbero (São Paulo), Brasil Antônio Fausto Neto, Universidade do Vale do Rio dos Sinos, Brasil Antonio Carlos Hohlfeldt, Pontifícia Universidade Católica do Rio Grande do Sul, Brasil Antonio Roberto Chiachiri Filho, Faculdade Cásper Líbero, Brasil Arthur Autran Franco de Sá Neto, Universidade Federal de São Carlos, Brasil Benjamim Picado, Universidade Federal Fluminense, Brasil César Geraldo Guimarães, Universidade Federal de Minas Gerais, Brasil Cristiane Freitas Gutfreind, Pontifícia Universidade Católica do Rio Grande do Sul, Brasil Denilson Lopes, Universidade Federal do Rio de Janeiro, Brasil Eduardo Peñuela Cañizal, Universidade Paulista, Brasil Eduardo Vicente, Universidade de São Paulo, Brasil Eneus Trindade, Universidade de São Paulo, Brasil Erick Felinto de Oliveira, Universidade do Estado do Rio de Janeiro, Brasil Florence Dravet, Universidade Católica de Brasilia, Brasil Gelson Santana, Universidade Anhembi/Morumbi, Brasil Gislene da Silva, Universidade Federal de Santa Catarina, Brasil Guillermo Orozco Gómez, Universidad de Guadalajara Gustavo Daudt Fischer, Universidade do Vale do Rio dos Sinos, Brasil Hector Ospina, Universidad de Manizales, Colômbia Herom Vargas, Universidade Municipal de São Caetano do Sul, Brasil leda Tucherman, Universidade Federal do Rio de Janeiro, Brasil Inês Vitorino, Universidade Federal do Ceará, Brasil Jnice Caiafa, Universidade Federal do Rio de Janeiro, Brasil Jay David Bolter, Georgia Institute of Technology Jeder Silveira Janotti Junior, Universidade Federal de Pernambuco, Brasil João Freire Filho, Universidade Federal do Rio de Janeiro, Brasil John DH Downing, University of Texas at Austin, Estados Unidos José Afonso da Silva Junior, Universidade Federal de Pernambuco, Brasil
José Carlos Rodrigues, Pontifícia Universidade Católica do Rio de Janeiro, Brasil José Luiz Aidar Prado, Pontifícia Universidade Católica de São Paulo, Brasil José Luiz Warren Jardim Gomes Braga, Universidade do Vale do Rio dos Sinos, Brasil Juremir Machado da Silva, Pontifícia Universidade Católica do Rio Grande do Sul, Brasil Laan Mendes Barros, Universidade Metodista de São Paulo, Brasil Lance Strate, Fordham University, USA, Estados Unidos Lorraine Leu, University of Bristol, Grã-Bretanha Lucia Leão, Pontifícia Universidade Católica de São Paulo, Brasil Malena Segura Contrera, Universidade Paulista, Brasil Márcio de Vasconcellos Serelle, Pontifícia Universidade Católica de Minas Gerais, Brasil Maria Aparecida Baccega, Universidade de São Paulo e Escola Superior de Propaganda e Marketing, Brasil Maria das Graças Pinto Coelho, Universidade Federal do Rio Grande do Norte, Brasil Maria Immacolata Vassallo de Lopes, Universidade de São Paulo, Brasil Maria Luiza Martins de Mendonça, Universidade Federal de Goiás, Brasil Mauro de Souza Ventura, Universidade Estadual Paulista, Brasil Mauro Pereira Porto, Tulane University, Estados Unidos Mirna Feitoza Pereira, Universidade Federal do Amazonas, Brasil Nilda Aparecida Jacks, Universidade Federal do Rio Grande do Sul, Brasil Paulo Roberto Gibaldi Vaz, Universidade Federal do Rio de Janeiro, Brasil Potiguara Mendes Silveira Jr, Universidade Federal de Juiz de Fora, Brasil Renato Cordeiro Gomes, Pontifícia Universidade Católica do Rio de Janeiro, Brasil Robert K Logan, University of Toronto, Canadá

Ronaldo George Helal, Universidade do Estado do Rio de Janeiro, Brasil Rose Melo Rocha, Escola Superior de Propaganda e Marketing, Brasil Rossana Reguillo, Instituto de Estudos Superiores do Ocidente, Mexico Rousiley Celi Moreira Maia, Universidade Federal de Minas Gerais, Brasil Sebastião Carlos de Morais Squirra, Universidade Metodista de São Paulo, Brasil Sebastião Guilherme Albano da Costa, Universidade Federal do Rio Grande do Norte, Brasil

Simone Maria Andrade Pereira de Sá, Universidade Federal Fluminense, Brasil Tiago Quiroga Fausto Neto, Universidade de Brasília, Brasil

Suzete Venturelli, Universidade de Brasilia, Brasil Valério Cruz Brittos, Universidade do Vale do Rio dos Sinos, Brasil Valerio Fuenzalida Fernández, Puc-Chile, Chile Veneza Mayora Ronsini, Universidade Federal de Santa Maria, Brasil Vera Regina Veiga França, Universidade Federal de Minas Gerais, Brasil

\section{COMISSÃO EDITORIAL}

Adriana Braga I Pontifícia Universidade Católica do Rio de Janeiro, Brasil

Felipe Costa Trotta I Universidade Federal Fluminense, Brasil

CONSULTORES AD HOC

Bruno Campanella, Universidade Federal Fluminense, Brasil

Gisela Grangeiro da Silva Castro, Escola Superior de Propaganda e Marketing, Brasi José Carlos Ribeiro, Universidade Federal da Bahia, Brasil

Luciana Panke, Universidade Federal do Paraná, Brasil

Micael Herschmann, Universidade Federal do Rio de Janeiro, Brasil

Tânia Márcia Cezar Hoff, Escola Superior de Propaganda e Marketing, Brasil

Virginia da Silveira Fonseca, Universidade Federal do Rio Grande do Sul, Brasil

EDIÇÃO DE TEXTO E RESUMOS I Susane Barros

SECRETÁRIA EXECUTIVA I Juliana Depiné

EDITORAÇÃO ELETRÔNICA I Roka Estúdio
COMPós I www.compos.org.br

Associação Nacional dos Programas de Pós-Graduação em Comunicação

Presidente

Julio Pinto

Pontifícia Universidade Católica de Minas Gerais, Brasil

juliopinto@pucminas.br

Vice-presidente

Itania Maria Mota Gomes

Universidade Federal da Bahia, Brasil

itania@ufba.br

Secretária-Geral

Inês Vitorino

Universidade Federal do Ceará, Brasil

inesvict@gmail.com 